\title{
Smart Canteen Management System Using RFID
}

\author{
${ }^{1}$ Akshatha Y, ${ }^{2}$ Rajath Bagre, ${ }^{3}$ Mohammed Mehar Ali Sabri, ${ }^{4}$ Nihal S Karkera, ${ }^{5}$ J Hima Nanaiah \\ ${ }^{1}$ Assistant Professor, ${ }^{2,3,4,5}$ B.Tech Student, Computer Science and Engineering, Presidency University, \\ Bangalore, India, 1akshathay@presidencyuniversity.in, 2rajathbagre652@gmail.com, \\ ${ }^{3}$ mehar1998ali@gmail.com, ${ }^{4}$ nihalkarkera1710@gmail.com, ${ }^{5}$ himananaiah12@gmail.com
}

\begin{abstract}
All the canteens in colleges and various companies use the traditional methods of payment. Students or employees pay their bills by cash. Cash payment is the only option available for making payments. Few canteens accept credit or debit cards but that is very rare. The proposed system provides Radio Frequency Identification(RFID) cards to the users. The card will be read and the users can choose their menu, this chosen menu will be sent to the user's registered phone number through an SMS and also to the chef. The payment will also be done through the card and the user will be notified with the balance deducted and the remaining balance. This system is IoT integrated as it makes the system more intelligent and flexible.
\end{abstract}

Keywords: RFID reader, RFID card, SMS, Arduino Nano, SMPS Order

\section{INTRODUCTION}

In Colleges, Schools or inside a University campus[5] canteen or Cafeteria facility is provided. Students, college staff or university staff use this facility. Similarly, canteen facilities are provided in various companies. In this canteen, students or employees pay their bills by cash as it is the only payment option available. Few canteens accept credit and debit cards but it is rare.

In this System, the canteen owner will provide RFID cards to the users or customers. The users can be students, college staff or employees. The users will have to[2] register themselves and recharge their cards in order to use the cards. The card can be used to make the payment as well as select the required menu. The menu selection can also be done using the application that is exclusively created for the canteen. The application helps the chefs to create the dish that is ordered before the customer reaches the canteen so that the customer does not have to wait after ordering.

\section{LITERATURE SURVEY}

In traditional Canteen Management System[10], Customers face many problems like security issues, lost account details, mistakes that happen due to manual works etc. The objective of the Smart Canteen Management System is to overcome the drawbacks of the traditional system.

In reference to the author[3], the current system of canteen management can be upgraded by integrating Internet of Things (IoT) with Radio Frequency Identification (RFID). This integrated system can make the existing system faster and efficient. RFID provides application to gather information about large number of customers, making it easier to process the data collected and also encourages cashless transactions.

With reference to the author[8], IoT enables transparency in the system to administrator as well as customer ends. This report will give the idea of how the existing system is managed using RFID and IoT.

\section{HARDWARE AND SOFTWARE REQUIREMENTS}

- RFID reader is a device used to gather information from the RFID tag.

- An RFID card contains an RFID tag that provides information to the RFID receiver through the waves generated.

- $\quad$ SMPS is an electronic power supply that incorporates a switching regulator to convert electrical power supply efficiently. It transfers power from AC or DC source to DC.

- Arduino Nano is an open source microcontroller. The board is equipped with sets of digital and analog input/output pins that may be interfaced to various expansion boards and other circuits.

- LCD is a flat panel display or other electronically modulated optical device that uses the light-modulating properties of liquid crystals combined with polarizers. Here it is used to display the menu and balance in the card.

- Keypad is used to provide input to the system like recharging the card, selecting the menu. 
- Buzzer is used for the conformation of user input.

- GSM module is used for communication between mobile phones and the system.

Software:

- Arduino IDE is the open source software to write the code and upload it to the board. It runs on Windows, Mac OS and Linux.

- C compiler is used to compile the code that has to be run.

- Android Studio is used to create a desired application as per the client requirement. It provides the fastest tools for building applications on every type of android device.

\section{IV.SYSTEM DESIGN}

This system can be divided into three parts:-

i. RFID card : The tag acts as responder in this system. It consists of a tiny radio transponder which has a radio receiver and a transmitter. When the tag is triggered by the electromagnetic wave from the reader, it transmits digital data, which is a unique electronic code attached to the object for identification. In the Canteen Management system the card is used to identify the customer so that the information about the customer can be read.

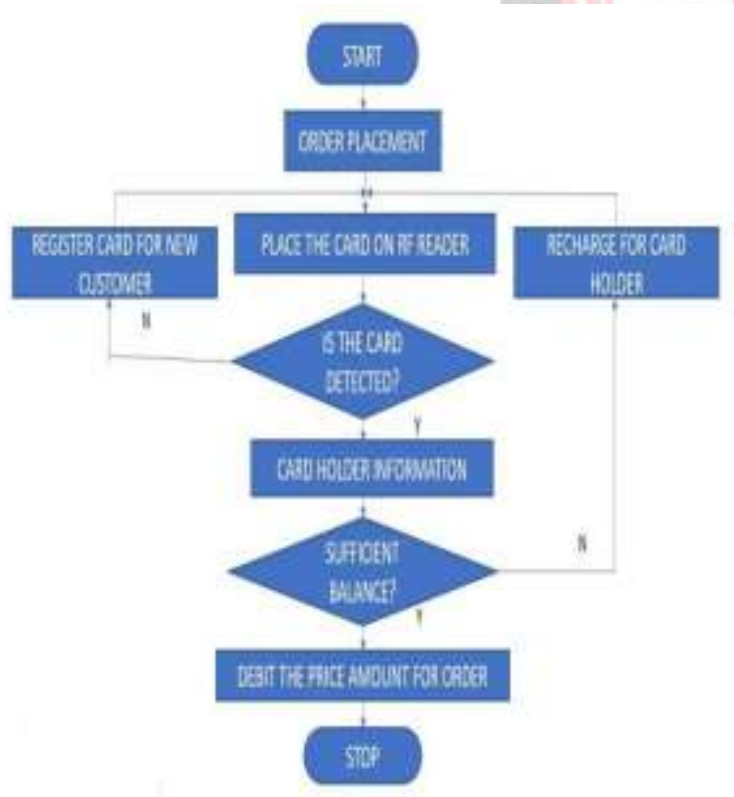

Fig.1 Workflow of the system

ii. RFID Reader: It used to gather information from the RFID tag to track individual objects. In this system the reader recognizes all the cards issued to the regular customers, so that they can be identified in the database and to obtain the information about the menu chosen, account balance and deduction.

iii. Software Application: The software application is used to register the information about the customer and assign the particular card in which this information is stored. It is also used to select menu and place orders of food as needed by the customers. The owner of the canteen can use it to check the details of orders, number of customers in a day and to manage other important things.

\section{IMPLEMENTATION}

\section{A. Working}

The order is placed through the application and the details of the order is sent to the chef and is displayed on the LCD panel and also to the customer's registered number through the SMS.

If the order cannot be placed through the application, it can also be done by placing the card on the RFID reader and by selecting the menu required. The payment is done when the customer places the card on the RFID reader after selecting the menu.

The details of balance will be sent to the customer's registered number after every transaction. The customer has the option to recharge his card as and when required.

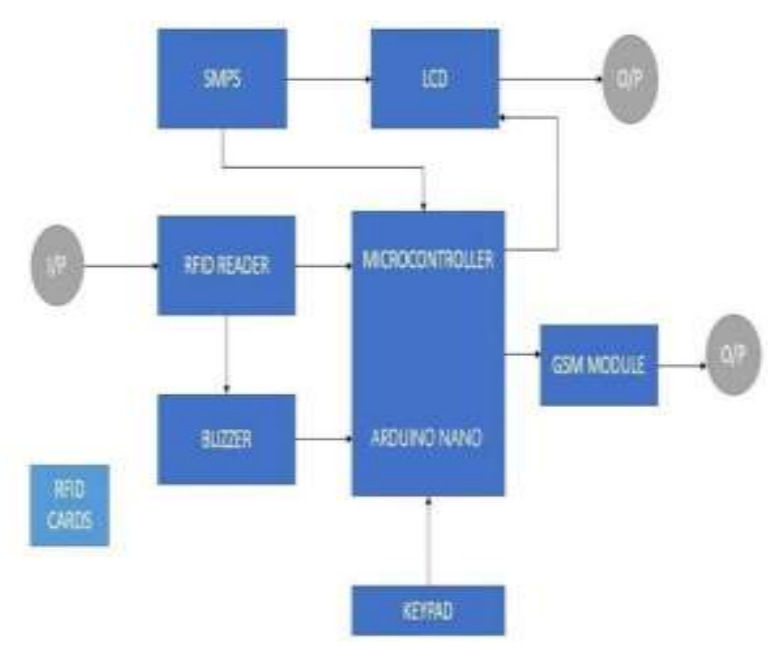

Fig. 2 Control flow diagram

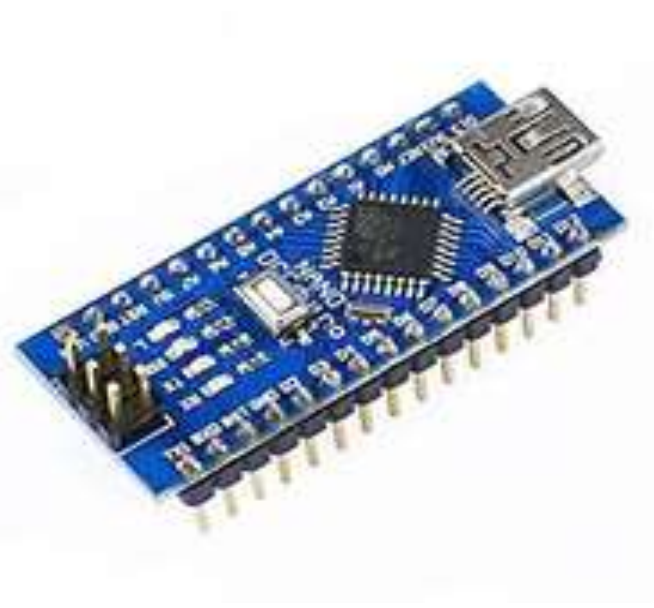

Fig.3: Arduino Nano 


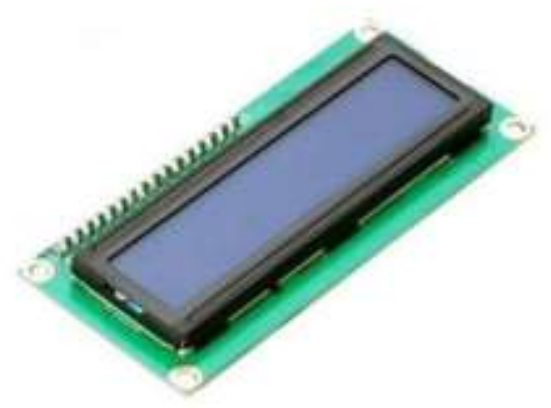

Fig.4: LCD

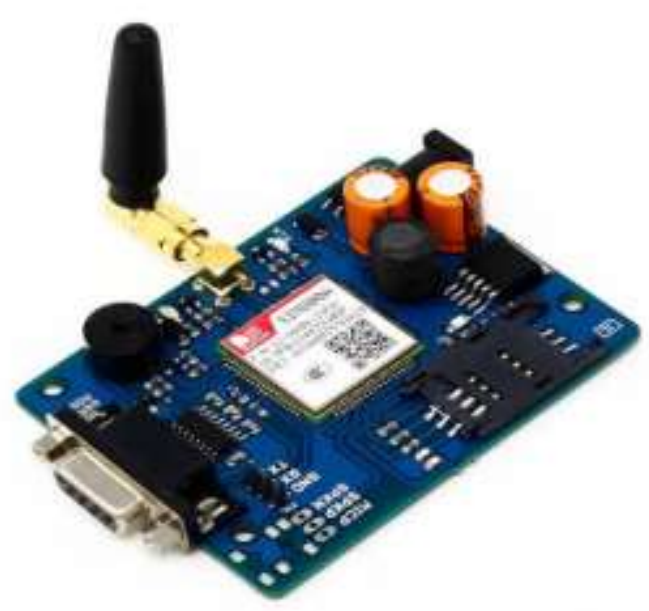

Fig. 5: GSM Module

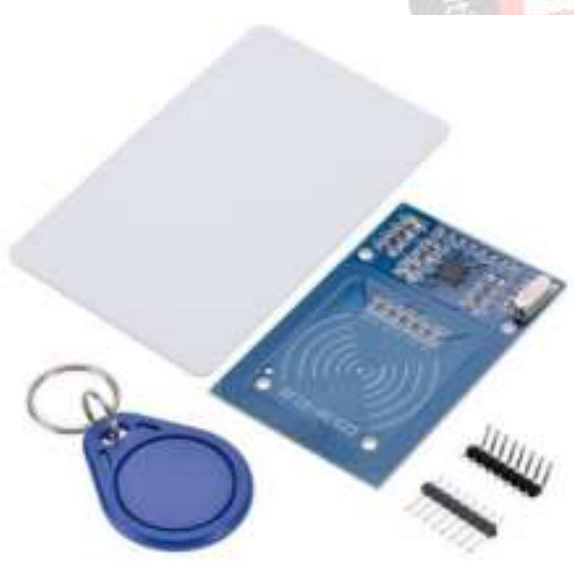

Fig.6: RFID Scanner

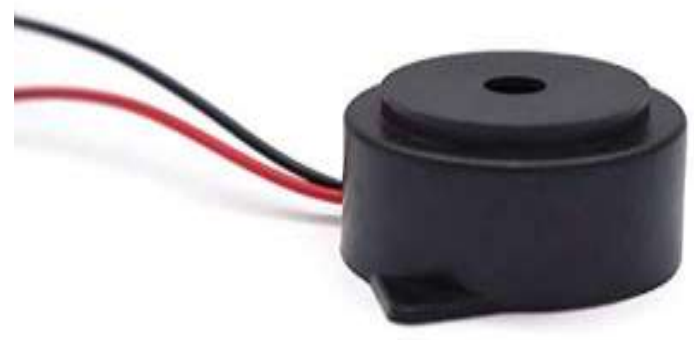

Fig.7: Buzzer

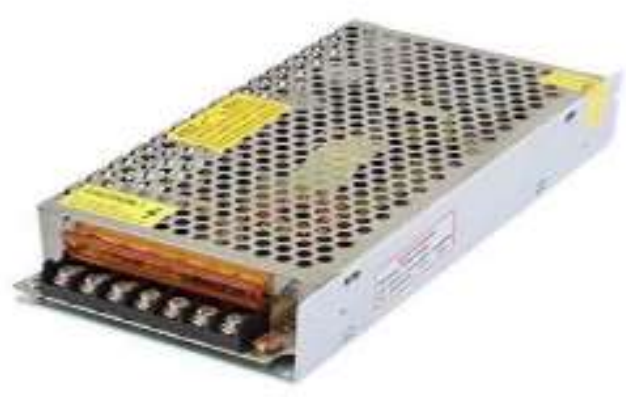

Fig.8: SMPS

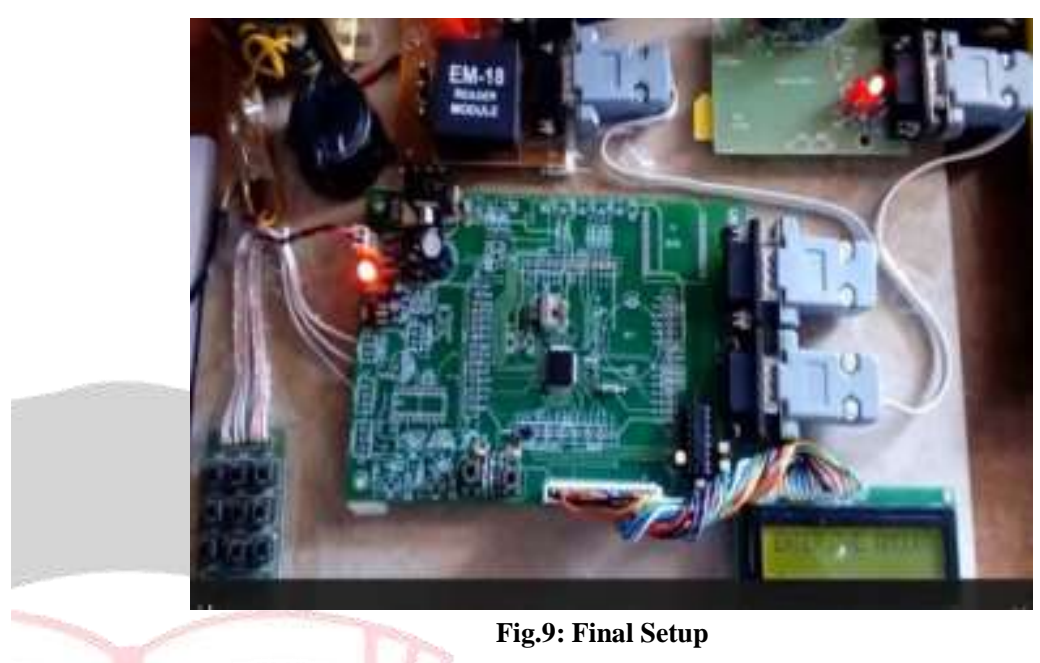

The card will be read and the menu will be selected to place order, then the amount will be deducted from the card and the order details will be sent to the chef as well as the user in the final system.

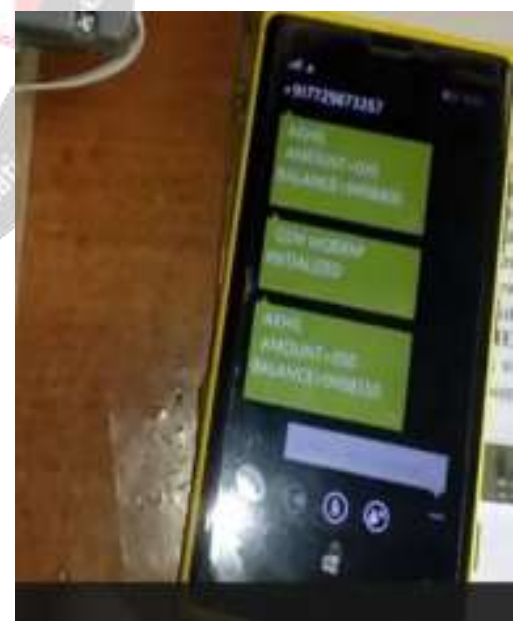

Fig. 10: Message identification

After placing the order, the registered user will receive a confirmation SMS in his registered phone number as shown above along with his card balance and the amount deducted.

\section{CONCLUSION}

The smart canteen management using RFID can be used in the canteens of school, college and various companies so that the work of the managers becomes simpler as managing the customers becomes easy. The 
user-friendly android application along with RFID card makes it even more simple for the customers since it saves their time. It helps the customers to place orders from anywhere within the campus and also helps them keep track of their card balance and food related updates.

The implementation of this system is more efficient than the traditional method as it becomes easy for the canteen owners to keep track of their customers and helps them manage the canteen system in a better way also, the customers can recharge their cars as and when they require. This will avoid confusion between the administrator and the customer regarding bills.

\section{REFERENCES}

[1] ] Student Card System Using Smart Card Technology -Information Technology Based Higher Education and Training, 2004. ITHET 2004.Proceedings of the Fifth International Conference in January 2004 from the University of New South Wales UNSW, Sydney, NSW 2052, Australia.

[2] Arun N Nambiar- RFID Technology: A Review of its Applications Proceedings of the World Congress on Engineering and Computer Science 2009 Vol ii WCECS 2009, October 20-22.

[3] Yao Xiaochun, Jiang Yuhong, “Canteen consuming management system design based on CAN bus and Radio Frequency Identification", Transportation, Mechanical, and Electrical Engineering(TMEE),2011 IEEE Conference.

[4] V.Bharani, S.Janani, Mr.A.Kanagasabapathy - STUDENTS AUTOMATION SYSTEM USING RFID - International Journal Of Engineering And Computer Science ISSN:2319-7242 Volume 3 Issue 3 March, 2014

Page No. 5031-5035

[5] "RFID based prepaid card for canteen management", Micro Technologies, Experts in Embedded and electronics systems.

[6] A. Ankit Kumar Jain, T. Rama Krishna, "Dynamic Book Search Using RFID Technology" International Journal of Engineering Research and General Science Volume 2, Issue 6, October-November, 2014, ISSN 2091-2730

[7] S SumithaNainan 1, Romin Parekh, Tanvi Shah - RFID Technology Based Attendance Management System from NMIMS University Mumbai, Maharashtra.

[8] "Internet of Things technology integrated experiment system type I" user manual by SHENZHEN HAITAINXIONG ELECTRONIC

\section{CO.,LTD.}

[9] Ashalatha R, Jayashree Agarkhed - Evaluation of Auto Scaling and Load Balancing Features in Cloud- International Journal of Computer Application (0975 8887) Volume 117 No. 6, May 2015 from P.D.A. College of Engineering, Kalaburagi, India.

[10] Somatic Madam, R. Ramaswamy, Siddharth Tripathi, "Internet of Things(IoT): A Literature Review", Journal of Computer and Communications, 2015, 3, 164-173. 